\title{
Effect of reservoir pay thickness on the performance of the THAI heavy oil and bitumen upgrading and production process
}

\author{
Muhammad Rabiu Ado ${ }^{1,2}$ (D)
}

Received: 29 August 2019 / Accepted: 16 January 2020 / Published online: 3 February 2020

(c) The Author(s) 2020

\begin{abstract}
The increasing energy demand has to be met while we transitioned to a decarbonized energy future. Heavy oil and bitumen reserves are urgently needed to be developed to ensure that a smooth transition is provided. In this work, field-scale kinetics parameters are used to study the effect of reservoir pay thickness on the performance of toe-to-heel air injection (THAI) process. Air was injected at constant rate into three different models with the thicknesses of $24 \mathrm{~m}, 16 \mathrm{~m}$, and $8 \mathrm{~m}$, respectively. The oil produced is slightly affected by the reservoir thickness. It is found that the lower the reservoir thickness, the larger the cumulative air-to-oil ratio (cAOR), indicating that heat loss increases with the decrease in the reservoir thickness. This trend is similar to steam-based processes. At constant air injection flux, it is found that both the cumulative oil produced and the cAOR decrease with the decrease in the reservoir thicknesses. This decrease is attributed to the decrease in the rate of heat generation in the thinner reservoirs, which in turn results in lower combustion zone temperature and thus lower temperature gradients between the reservoir and the overburden and the reservoir and the underburden. Consequently, a more general conclusion is that decreasing the air injection rate by the same factor the reservoir thickness is decreased (i.e. keeping the air injection flux constant) results in a more economical THAI process operation compared to when the air injection rate is kept constant (i.e. allowing increase in air injection flux).
\end{abstract}

Keywords Reservoir pay thickness · Toe-to-heel air injection (THAI) · Enhanced oil recovery (EOR) - In situ combustion (ISC) $\cdot$ Reservoir simulation · Bitumen/heavy oil

\section{Introduction}

According to the U.S. Geological Survey report (Meyer et al. 2007), worldwide, the total reserves of heavy oil and bitumen are estimated to be approximately 8901 billion barrels of oil originally in place (OOIP). This is approximately two times the reserves of conventional light oils (Le Ravalec et al. 2009). These unconventional resources have been predicted by IEA to provide an increasing share towards meeting overall energy demand as we transitioned to a decarbonized energy mix (Mashayekhizadeh et al. 2011a, b; Dejam

Muhammad Rabiu Ado

mado@kfu.edu.sa

1 Department of Chemical Engineering, College of Engineering, King Faisal University, P.O. Box: 380, Al-Ahsa 31982, Kingdom of Saudi Arabia

2 Department of Chemical and Environmental Engineering, University of Nottingham, University Park, Nottingham NG7 2RD, UK et al. 2011, 2013, 2018). This is necessary given that there is hardly any substitute in catering for the demand by the transportation and petrochemicals sectors. As a result, heavy oil and bitumen reserves are urgently needed to be developed to ensure that a smooth transition to a decarbonized energy future is provided (Saboorian-Jooybari et al. 2015, 2016; Amirian et al. 2018; Dejam 2018). However, the unconventional recourses, such as bitumen and heavy oil, are very difficult to produce especially when the fact that they have very high viscosity and are typically immobile at the reservoir conditions is considered. The current steam-based heavy oil/ bitumen recovery processes, such as steam-assisted gravity drainage (SAGD), cyclic steam stimulation (CSS), and steam flooding (SF), have been shown to have limited applicability, e.g. they can be only safely and economically applied to the select few reservoirs having pay thicknesses of at least $15 \mathrm{~m}$ (Gates 2010; Zhao et al. 2013, 2014). In addition to that, these technologies are not environmentally friendly as they emit substantial amount of carbon dioxide $\left(\mathrm{CO}_{2}\right)$ in the period of steam generation, have low efficiencies since

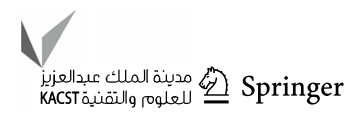


they suffer from considerable wellbore heat losses, require considerable waste water handling and purification, and they do not provide appreciable oil upgrading within the reservoir (Gates and Larter 2014; Shi et al. 2017; Wang et al. 2019). Furthermore, in some of the field pilot cases, SAGD was shown to not be a net energy producer (Gates and Larter 2014). Given the increasing global concern with regard to climate change and the Paris accord on climate change requiring a significant lowering of the greenhouse gas emissions so that the global average temperature is limited to significantly below $2{ }^{\circ} \mathrm{C}$ above pre-industrial levels, the substantial portion of the bitumen and heavy oil upgrading should be, as much as practicable, carried out within the reservoirs. The extraction technology needed to produce these unconventional resources should also be capable of minimizing the surface footprint of the upgrading refinery, should be less water intensive, and should have high recovery factors. This is where toe-to-heel air injection (THAI) bitumen and heavy oil upgrading and production process comes in.

The THAI process is a variation of conventional in situ combustion (ISC) that uses a horizontal well technology for heavy oil mobilization, upgrading, and production. In THAI, a combination of coke combustion reaction, heat-, mass-, and gas-momentum transfer, and gravity drainage is used to mobilize and upgrade the heavy oil to the surface (Xia and Greaves 2002; Turta and Singhal 2004; Xia et al. 2005; Greaves et al. 2008). It is a "short distance displacement" process that uses, at experimental level, horizontal wells for both injection and production (i.e. HIHP configuration). In some experimental and all field cases, vertical injector(s) is/ are used in combination with horizontal producer(s) either arranged in direct-line drive (DLD) (i.e. VIHP configuration) or staggered-line drive (SLD) (i.e. 2VIHP configuration). Experimentally, the THAI process was shown to be highly efficient as more than $80 \%$ of OOIP is usually recovered. Many variables, such as optimum fuel laydown ahead of the combustion front, optimum pre-heating prior to air injection, continuous air injection, etc., have been identified as affecting the stability of combustion front propagation and sustenance in the THAI process. The main advantages of the THAI process, in situ combustion, and the conditions for process stability are summarized elsewhere (Turta and Singhal 2004; Xia et al. 2005; Greaves et al. 2008; Gutierrez et al. 2009; Liang et al. 2012; Rabiu Ado et al. 2017; Rahnema et al. 2017; Rabiu Ado et al. 2018; Zhao et al. 2018; Chen et al. 2019; Zhao et al. 2019). Furthermore, the THAI process has been the subject of detailed numerical simulations both at laboratory scale and at field scale (Rabiu Ado et al. 2017, 2018; Ado et al. 2019; Ado 2019, 2020a, b).

Despite the fact that the THAI process was proven to effectively solve many problems associated with conventional ISC and offer many advantages over other heavy oil recovery techniques, a lot of work has to be done to fully realize its theoretical promise. In the previous work (Ado et al. 2019), it has been shown through numerical simulations that the THAI process is only marginally affected by reservoir heterogeneity, which is unlike the case with the other thermal recovery processes, such as SAGD and CSS (Le Ravalec et al. 2009; Su et al. 2013, 2014; Fatemi 2012). However, there is only one experimental study (Xia et al. 2002), but no simulation study in the literature which investigated the effect of reservoir pay thickness on the performance of the THAI process. This is particularly useful given that about $25 \%$ of the heavy oil and bitumen reservoirs in the Alberta region of Canada, which contain approximately 1.7 trillion barrels of heavy oil and bitumen, have pay thicknesses of at most $10 \mathrm{~m}$ (Gates 2010). As a result, different studies have looked at the effect of reservoir thickness on the performance of SAGD, CSS, and SF (Al-Bahlani and Babadagli 2009; Gates 2010; Zhao et al. 2013, 2014; Huang et al. 2019). All of these studies have concluded that steambased processes, when applied to thin reservoirs, suffer from substantial heat losses to both underburden and overburden, which in turn lead to significant loss of efficiencies. As a consequence, some of these studies have concluded that expanding solvent SAGD (ES-SAGD) process should be used to lower steam injection rate and to at least provide similar performance as that of SAGD in thicker reservoirs (Gates 2010; You et al. 2012), which was not shown to be the case. Other studies concluded the use of hot water flooding process is a better alternative to steam-based processes in thin reservoirs (Zhao et al. 2014), since the temperature gradient will become lower and hence results in decreased rate of heat loss. Still, some studies look at the use of cyclic superheated steam stimulation alone (Sun et al. 2017a, b) or in combination with $\mathrm{CO}_{2}$ (Sun et al. 2018) for heavy oil recovery.

Given the above findings on the other thermal heavy oil and bitumen recovery processes, it is critical to investigate the performance of the THAI process when applied to different reservoir thicknesses. This will allow its potential for use in thinner reservoirs to be determined and thus allow its full theoretical promise to be realized. To do so, numerical simulations were performed using a thermal reservoir simulator, CMG STARS. Two sets of the same reservoir model, but with three different oil layer thicknesses based on the properties of the Athabasca bitumen, which is located in Alberta, Canada, were developed. The first set of three models, which have reservoir thicknesses of $24 \mathrm{~m}, 16 \mathrm{~m}$, and $8 \mathrm{~m}$, respectively, has the same constant air injection rate of $20,000 \mathrm{Sm}^{3} / \mathrm{day}$. For the second set, the air rate was varied, thereby keeping the air injection flux constant at $0.347 \mathrm{Sm}^{3} / \mathrm{m}^{2} \cdot \mathrm{h}$, which is within the range of the fieldscale values reported by different authors as summarized by Alamatsaz et al. (2019). These allow comparative studies to be made. 


\section{Simulation models development}

This work uses an upscaled CMG STARS thermal reservoir simulator model which is previously developed and validated against experimental results by Rabiu Ado et al. (2017). The experimental scale model, which was based on optimum gridblock size, was shown to be able to predict both steady-state and dynamic physicochemical processes governing the THAI process. The upscaled model, which is very well detailed in Rabiu Ado (2017), is then used in this study. Firstly, the model dimensions will be considered. In all the first set of the three models, the wells are arranged in a staggered-line drive (SLD) and the only dimension varied is the thickness of the reservoir, which is represented by $x$ (Fig. 1). $x$ has three values, namely $24 \mathrm{~m}, 16 \mathrm{~m}$, and $8 \mathrm{~m}$ for each of the models, respectively. The same applies to the second set of the three models. In all the models, the location of the horizontal producer (HP) relative to the base of the reservoir was kept constant (i.e. $1.5 \mathrm{~m}$ above the base of the reservoir).

In each case, the reservoir was discretized into 30 in $x$-direction, 19 in $y$-direction, and 7 in $z$-direction (i.e. 5.000 $\left.\hat{i}(\mathrm{~m}) \times 5.263 \hat{j}(\mathrm{~m}) \times\left(\frac{x}{7}\right) \hat{k}(\mathrm{~m})\right)$ parent gridblocks and each parent gridblock in each model was subdivided (i.e. "REFINE") into 3 in $x$-, 3 in $y$-, and 1 in $z$-directions. Therefore, in each model, the total number of small-sized gridblocks was 38,500 (i.e. including the gridblocks of the discretized wellbore model). The DYNAGRID option, which allows the simulator to dynamically change the gridblock size from that of child gridblock to that of parent gridblock when certain conditions are met, is used. This is in accordance with the optimum gridblock selection determined using the experimental scale model. The conditions set in the simulator for the dynamic gridblock refinement and derefinement is such that if the global mole per cent of any component is less than $3 \mathrm{~mol} \%$, oil mole per cent is less than $2 \mathrm{~mol} \%$, pressure variation is within $20 \mathrm{kPa}(2.90 \mathrm{psi})$, gridblock temperature variation is within $30^{\circ} \mathrm{C}$, etc., then the gridblock sizes should be restored to their original dimensions before refinement.

Just like in the previously published studies (Rabiu Ado et al. 2017, 2018; Ado et al. 2019), the discretized wellbore model (DWM) option available in the CMG STARS was used in each model. This allowed the heat, mass, and momentum transfer to be rigorously represented in the well, and the resulting well equations coupled to the reservoir equations for simultaneous solutions. The Algebraic equations resulting from the discretizations of the reservoir and the DMW are solved by the CMG's STARS simulator using a fully implicit finite difference method on a computer having two 8-core parallel processors. However, prior to obtaining the solutions, some input parameters must be specified in the simulator.

\section{Petrophysical parameters}

This work is carried out using Athabasca bitumen, since the original model validated by Rabiu Ado et al. (2017) is based on the experimental upgrading of the Athabasca bitumen. Consequently, the reservoir porosity is taken from Rabiu Ado et al. (2017) and is shown in Table 1. For the absolute permeability, the oil saturation, and the water saturation, the same field values as reported by Petrobank (2010) are used (Table 1). Other petrophysical parameters, such as the relative permeability curves, can be found in previous work (Rabiu Ado et al. 2017) and, as a result, will not be reproduced here.

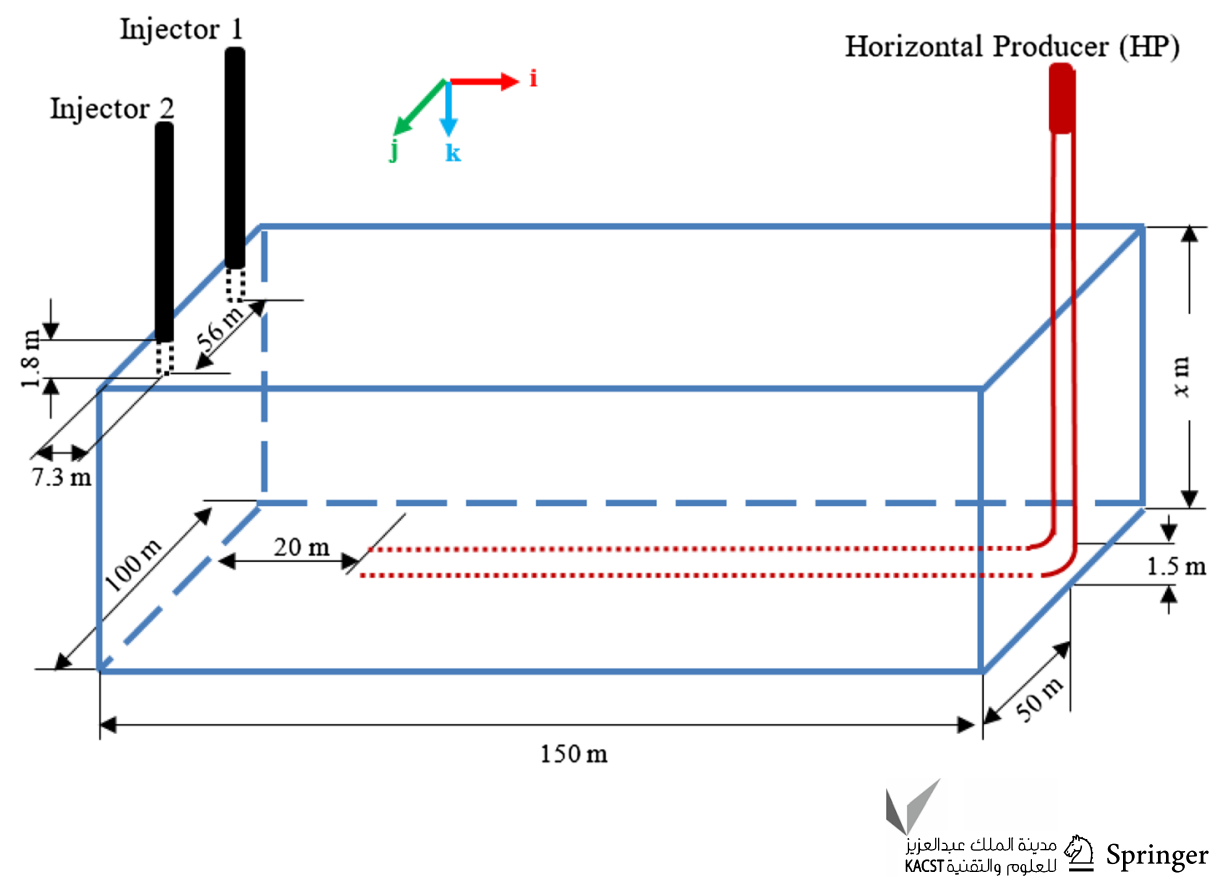

Fig. 1 Reservoir model dimensions showing the wells arrangement, where $x$ has values of $24 \mathrm{~m}, 16 \mathrm{~m}$, or $8 \mathrm{~m}$, respectively 
Table 1 Fluid saturation, porosity, and absolute permeability

\begin{tabular}{lllll}
\hline$S_{\mathrm{O}}$ & $S_{\mathrm{W}}$ & Porosity & $\begin{array}{l}\text { Vertical permeability } \\
(\mathrm{md})\end{array}$ & $\begin{array}{l}\text { Horizontal perme- } \\
\text { ability (md) }\end{array}$ \\
\hline 0.80 & 0.20 & 0.34 & 3450 & 6400 \\
\hline
\end{tabular}

\section{Pressure-volume-temperature (PVT) data}

The same PVT data as detailed in the previous work (Rabiu Ado et al. 2017, 2018) are used in this work. As a consequence and for consistency, only the tabulated properties of the different oil pseudo-components are shown in Table 2. Their respective viscosity variations with the temperature and $\mathrm{K}$-values variations with temperature and pressure are not shown. If you need more information, please refer to the work of Rabiu Ado et al. (2017).

\section{Field-scale THAI kinetics}

It has been extensively shown by many authors (Hwang et al. 1982; Coats 1983; Ito and Chow 1988; Marjerrison and Fassihi 1992; Kovscek et al. 2013; Nissen et al. 2015; Rabiu Ado 2017) that the kinetics parameters derived from validating laboratory-scale experiments cannot be used to model field-scale in situ combustion. Therefore, in this study, the field-scale kinetics parameters for the Athabasca bitumen, which were derived by Rabiu Ado (2017), are used (Tables 3 and 4).

\section{Initial and boundary conditions}

In each model, the initial oil and water saturations are, respectively, $80 \%$ and $20 \%$. Also, the initial reservoir temperature and pressure are $20^{\circ} \mathrm{C}$ and $2800 \mathrm{kPa}(406.11 \mathrm{psi})$, as reported by Petrobank (2010), respectively. Each well (i.e. the vertical injectors (2VI) and the horizontal producer (HP)) has an internal diameter of $178 \mathrm{~mm}$ (7.01 inch). Heat loss, which occurred via conduction only, was assumed to

Table 2 PVT data used in this study, where LC, MC, and IC are defined as the light, mobile, and immobile pseudo-components, respectively

\begin{tabular}{llll}
\hline Pseudo-components & LC & MC & IC \\
\hline Fraction (mol\%) & 42.50 & 23.91 & 33.59 \\
Molecular weight $(\mathrm{g} / \mathrm{mol})$ & 210.8 & 496.81 & 1017.01 \\
$\mathrm{P}_{\mathrm{C}}(\mathrm{kPa})$ & 1682.88 & 1038.46 & 729.22 \\
$(\mathrm{psi})$ & $(244.08)$ & $(150.62)$ & $(105.76)$ \\
$\mathrm{T}_{\mathrm{C}}\left({ }^{\circ} \mathrm{C}\right)$ & 464.68 & 698.53 & 940.36 \\
$\mathrm{P}\left(\mathrm{kg} \mathrm{m}^{-3}\right)$ & 828.24 & 961.66 & 1088.04 \\
Eccentricity & 0.62 & 1.18 & 1.44 \\
$\mathrm{~T}_{\mathrm{B}}\left({ }^{\circ} \mathrm{C}\right)$ & 281.47 & 549.67 & 785.78 \\
\hline
\end{tabular}

Table 3 Field-scale thermal cracking reaction schemes and their kinetics parameters (Rabiu Ado 2017)

\begin{tabular}{llll}
\hline S/no. & Thermal cracking reactions & $\begin{array}{l}\text { Frequency fac- } \\
\text { tor }\left(\mathrm{min}^{-1}\right)\end{array}$ & $\begin{array}{l}\text { Act. energy } \\
(\mathrm{kJ} / \mathrm{mol})\end{array}$ \\
\hline 1 & $\mathrm{IC} \rightarrow 2.0471 \mathrm{MC}$ & $8.186 \times 10^{16}$ & 239.01 \\
2 & $\mathrm{MC} \rightarrow 0.4885 \mathrm{IC}$ & $7.209 \times 10^{14}$ & 215.82 \\
3 & $\mathrm{MC} \rightarrow 2.3567 \mathrm{LC}$ & $2.425 \times 10^{11}$ & 184.88 \\
4 & $\mathrm{LC} \rightarrow 0.4243 \mathrm{MC}$ & $3.264 \times 10^{11}$ & 180.45 \\
5 & $\mathrm{IC} \rightarrow 77.4563 \mathrm{COKE}$ & $4.969 \times 10^{11}$ & 180.88 \\
\hline
\end{tabular}

take place via both the overburden and underburden. All over the reservoir, no flow boundary condition was assumed except through both the vertical injectors and the horizontal producer. In each model, each VI well was flow-controlled with steam injected at different rates depending on the reservoir thickness (Table 5). The saturated steam, at $5500 \mathrm{kPa}$ (797.71 psi) and quality of 0.8 , was injected for a period of 104 days of pre-ignition heating cycle (PIHC) at the maximum rates specified in Table 5. It should be noted that the steam injection rate through each of the VI well is half of the total shown in Table 5. Thereafter, air was injected for a period of 2 years in each model. In the case of the HP well, maximum bottom hole pressure (BHP) of $2800 \mathrm{kPa}$ (406.11 psi) was used to control the producer back pressure and maintain the reservoir at that pressure.

\section{Results and discussions}

\section{Start-up: pre-ignition heating cycle (PIHC) period}

Prior to air injection and initiation of combustion, steam must be injected for two reasons: (1) to condition the inlet zone of the vertical injectors (VIs) so that enough immobile fraction of the heavy oil is deposited to initiate and sustain a stable combustion front, and (2) to heat up and mobilize the oil near the VI wells to establish fluid communication with the HP well. In their white sand field trial, Petrobank (2010) determined that the optimum steam injection period for the pre-ignition heating cycle (PIHC) is 104 days. As a result, this study has used 104 days as the duration of the PIHC for both the two sets of the three models. For the first set of the three models, at the end of the PIHC, apart from fully establishing communication between the wells, the oil recovered is shown in Table 6 . These values are the same as those obtained with the second set of the three models, since all the sets have the same start-up methods and it is only the air injection rates, which takes place after the PIHC, that differ.

The above values of the per cent oil recovery (Table 6) at the end of the PIHC are quite similar to the $4 \%$ OOIP 
Table 4 Field-scale combustion reactions schemes and their kinetics parameters (Rabiu Ado 2017)

\begin{tabular}{llll}
\hline Combustion reactions & $\begin{array}{l}\text { Frequency factor } \\
(\mathrm{kPa} \text { min })^{-1}\end{array}$ & $\begin{array}{l}\text { Activation } \\
\text { energy (kJ/mol) }\end{array}$ & $\begin{array}{l}\text { Heat of reac- } \\
\text { tion }(\mathrm{kJ} / \mathrm{mol})\end{array}$ \\
\hline $\mathrm{IC}+98.869 \mathrm{O}_{2} \rightarrow 77.456 \mathrm{CO}_{1.947}+46.904 \mathrm{H}_{2} \mathrm{O}$ & $2.772 \times 10^{3}$ & 138.00 & $4.00 \times 10^{4}$ \\
$\mathrm{MC}+49.069 \mathrm{O}_{2} \rightarrow 37.075 \mathrm{CO}_{1.947}+25.953 \mathrm{H}_{2} \mathrm{O}$ & $2.772 \times 10^{4}$ & 138.00 & $1.60 \times 10^{4}$ \\
$\mathrm{LC}+32.025 \mathrm{O}_{2} \rightarrow 14.600 \mathrm{CO}_{1.947}+35.623 \mathrm{H}_{2} \mathrm{O}$ & $2.772 \times 10^{5}$ & 138.00 & $4.91 \times 10^{2}$ \\
$\mathrm{COKE}+1.22 \mathrm{O}_{2} \rightarrow \mathrm{CO}_{1.875}+0.565 \mathrm{H}_{2} \mathrm{O}$ & $1.530 \times 10^{5}$ & 123.00 & $3.90 \times 10^{2}$ \\
\hline
\end{tabular}

Table 5 Average steam injection rate for the PIHC

\begin{tabular}{ll}
\hline Reservoir thickness $(\mathrm{m})$ & $\begin{array}{l}\text { Average saturated steam injection rate cold water } \\
\text { equivalent }(\mathrm{CWE} \text { bbl/day) at } 5500 \mathrm{kPa}(797.71 \mathrm{psi}) \text { and } \\
\text { with quality of } 0.8\end{array}$ \\
\hline 24 & 400 maximum of (495) \\
16 & 327 maximum of (330) \\
8 & 165 maximum of (165) \\
\hline
\end{tabular}

Table 6 Oil recovery at the end of the 104 days of PIHC

\begin{tabular}{lll}
\hline Reservoir thickness $(\mathrm{m})$ & Cumulative oil recovered $\left(\mathrm{m}^{3}\right)$ & $\begin{array}{l}\% \text { OOIP } \\
\text { recovery }\end{array}$ \\
\hline 24 & 2883 & 3.10 \\
16 & 2871 & 4.62 \\
8 & 1255 & 4.04 \\
\hline
\end{tabular}

recovery achieved in the experiment (Xia and Greaves 2002) as well as the experimental model (Rabiu Ado et al. 2017). This shows that the selected duration of the PIHC is reasonable since it is capable of emulating both the physical experiment and the validated laboratory-scale model.

\section{Constant air injection rate models}

The use of steam during the PIHC of the THAI process has shown that the process behaves like SAGD, in that, it suffers from heat loss to both overburden and underburden, which is reflected by the cumulative oil produced. However, if we considered the per cent oil recovery, the THAI process is not affected by the reservoir thickness during the PIHC period. For the first set of the three models (i.e. with the reservoir thicknesses of $24 \mathrm{~m}, 16 \mathrm{~m}$, and $8 \mathrm{~m}$, respectively), at the end of the PHIC, air was injected at the rate of $20,000 \mathrm{Sm}^{3} /$ day (i.e. $10,000 \mathrm{Sm}^{3} /$ day via each injector) regardless of the reservoir thickness. As a result, we refer them as the constant air injection rate models, since by keeping the air injection rate the same in each model, the rate of heat generation will be the same, and hence, a comparative study can be made about the extent of heat loss out of the reservoir. The air injection flux, however, is variable. Therefore, the air injection fluxes are $0.347,0.521$, and $1.042 \mathrm{~m}^{3} / \mathrm{m}^{2} \cdot \mathrm{h}$ for the reservoir thicknesses of $24 \mathrm{~m}, 16 \mathrm{~m}$, and $8 \mathrm{~m}$, respectively.

\section{Oil production rate}

Prior to air injection, the oil production rate showed great variation, with that in the model with reservoir thickness of $24 \mathrm{~m}$ being produced a little later ( 2 weeks later). Notice, as reflected in Table 6, the lower the reservoir thickness, the lower the oil production rate curve, which can be attributed to heat loss. As the air injection began at 104 days and at the rate of $20,000 \mathrm{Sm}^{3} /$ day regardless of the reservoir thickness, the oil production rate curves overlap each other (Fig. 2). When the reservoir thickness is $24 \mathrm{~m}$ or $16 \mathrm{~m}$, the oil production rate was maintained more or less the same throughout the 2 years of combustion. In the case of reservoir with thickness of $8 \mathrm{~m}$, however, over 270 to 350 days, the oil production rate steadily peaked reaching a maximum of $52 \mathrm{~m}^{3} /$ day before declining back to steady-state rate of $36 \mathrm{~m}^{3} /$ day. The period of 270 to 350 days corresponds to when the combustion zone reached the heel of the horizontal producer (HP) and more oil flows from either side of the producer. This is because the combustion front can no longer advance along the axis of the HP well, but can only expand radially/laterally (see Figs. 4 and 5, which will be explained in more detail).

\section{Cumulative oil production}

For the reservoir thicknesses of $24 \mathrm{~m}$ and $16 \mathrm{~m}$, the cumulative oil production curves match just before and immediately after the start of air injection (Fig. 3). As air was continuously injected, the cumulative oil production curve for the reservoir thickness of $16 \mathrm{~m}$ slightly diverged away from that of the model with the reservoir thickness of $24 \mathrm{~m}$, laying below the latter for the rest of the combustion time. By the end of the 2 years of air injection and combustion, $28,700 \mathrm{~m}^{3}$ of oil is approximately recovered in model with

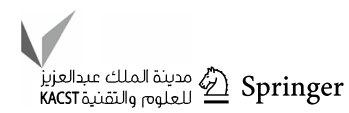


Fig. 2 Oil production rate for the different reservoir thicknesses at constant air injection rate
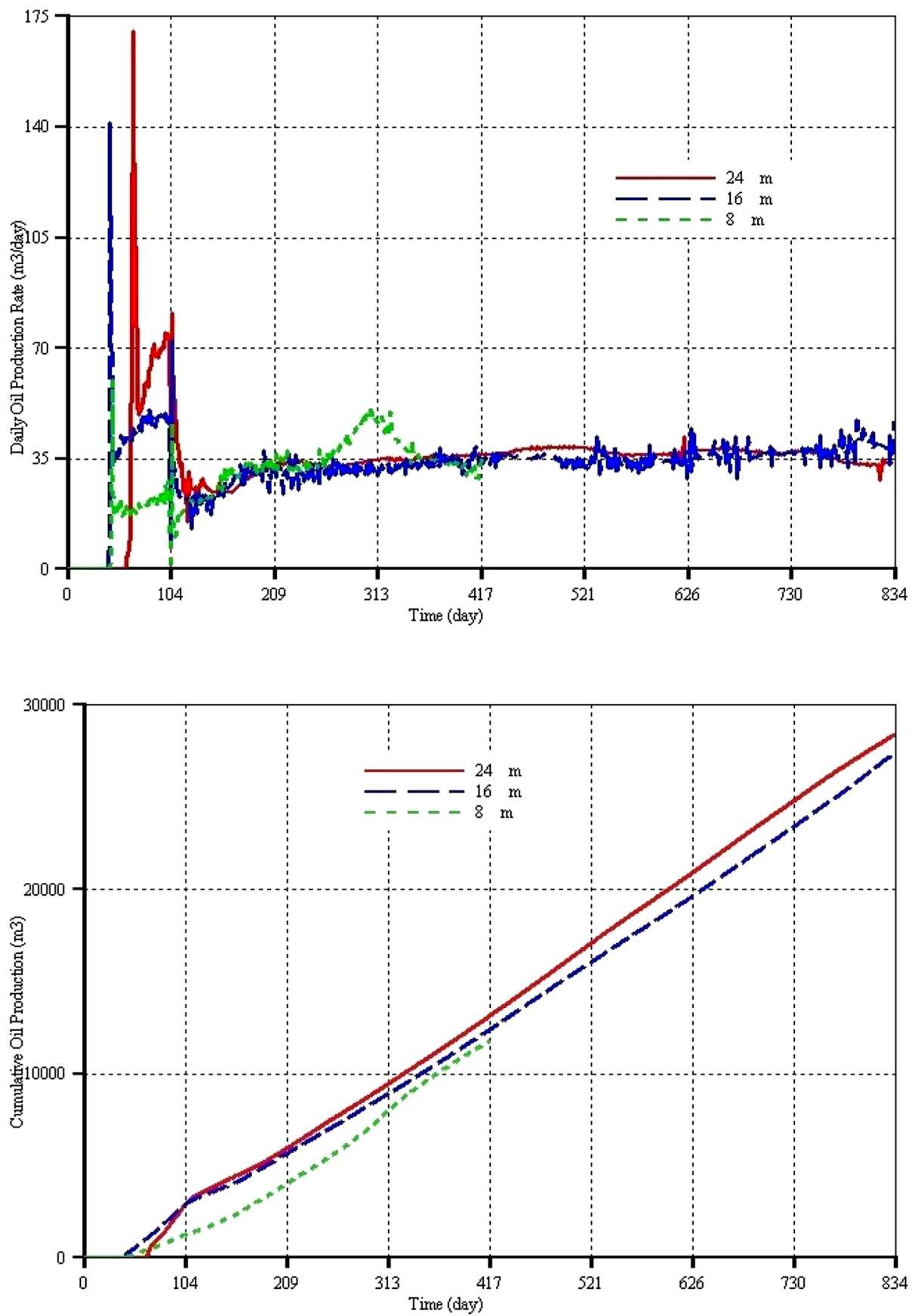

Fig. 3 Cumulative oil production for the different reservoir thicknesses at constant air injection rate the reservoir thickness of $24 \mathrm{~m}$, which is roughly $4.6 \%$ (i.e. $1320 \mathrm{~m}^{3}$ ) more than that recovered when the reservoir thickness is $16 \mathrm{~m}$. Since at the end of the PIHC period, the cumulative oil produced when the reservoir thickness is $24 \mathrm{~m}$ is only $12 \mathrm{~m}^{3}$ greater than when the reservoir thickness is $16 \mathrm{~m}$ (Table 6), it follows that $1308 \mathrm{~m}^{3}$ more oil produced when the reservoir thickness is $24 \mathrm{~m}$ is due to combustion only. When the reservoir thickness was further decreased to $8 \mathrm{~m}$, the combustion was only run for 10.5 months. This was due to the limitation placed by the simulator as the process time step became so small that it was not feasible to allow the simulation to carry on. The decrease in the time step to very small values was due to the combustion front reaching the horizontal producer, making the simulation highly difficult due to increase in nonlinearity (see Fig. 4, which will be explained later). At the 417 days, less oil is cumulatively produced by $3.54 \%$ (i.e. $12180 \mathrm{~m}^{3}$ ) when the reservoir thickness is $8 \mathrm{~m}$ compared to $12,610 \mathrm{~m}^{3}$ when it is $16 \mathrm{~m}$. At the same time, $13,480 \mathrm{~m}^{3}$ of oil is cumulatively produced when the reservoir thickness is $24 \mathrm{~m}$.

Qualitatively, and when compared to SAGD and other steam-based processes, it can be seen that the reservoir 


\section{Gas Mole Fraction (O2) 417 days}

(a)

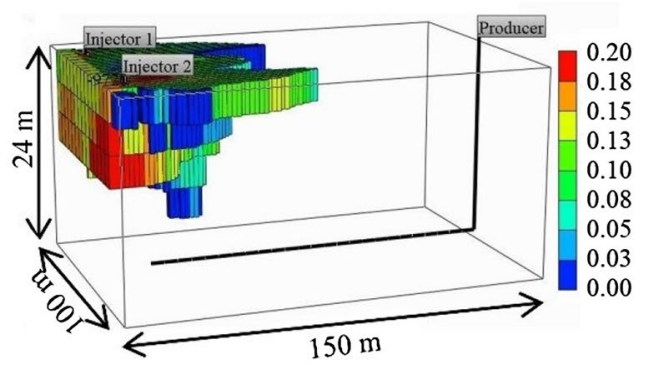

Gas Mole Fraction (O2) 417 days J layer: 10

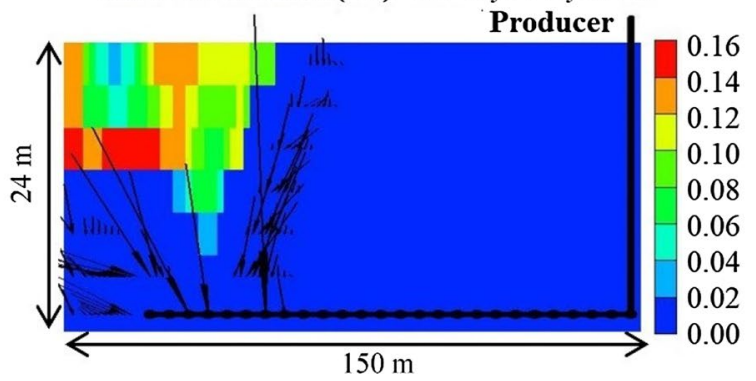

Oil layer thickness: $24 \mathrm{~m}$

Gas Mole Fraction (O2) 417 days J layer: 10

(b)

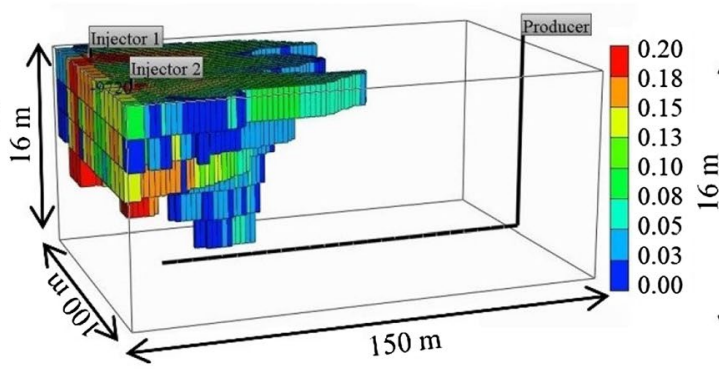

Gas Mole Fraction (O2) 417 days J layer: 10

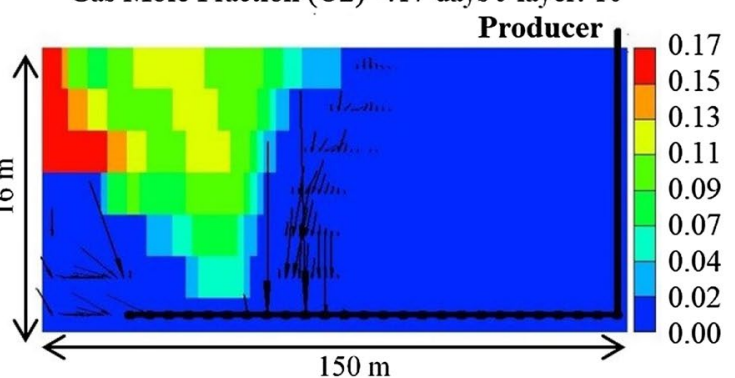

Oil layer thickness: $16 \mathrm{~m}$
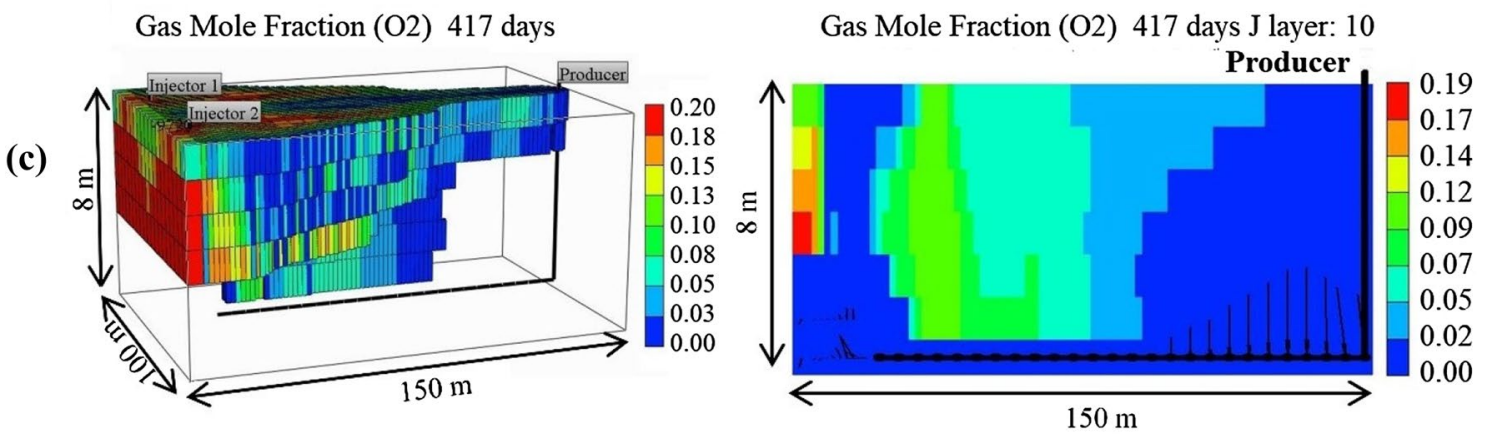

Oil layer thickness: $8 \mathrm{~m}$

Fig. 4 3D shape of the combustion front (left) and the oxygen concentration profiles along the vertical mid-plane (right) at 417 days and at constant air injection rate

thickness do not have adverse effect on the cumulative oil recovered (Fig. 3) and hence the economy of the THAI process. This is quite similar to the observation made by Xia et al. (2002) when they experimentally studied the effect of oil layer thickness on oil recovery in the THAI process. The justification is that the maximum difference in cumulative oil produced over the 2 years of combustion is $1320 \mathrm{~m}^{3}$ (i.e. between thickness of $24 \mathrm{~m}$ and $16 \mathrm{~m}$ ) and over the 10.5 months of combustion is $1300 \mathrm{~m}^{3}$ (i.e. between thickness of $24 \mathrm{~m}$ and $8 \mathrm{~m}$ ). To support this fact, the cumulative air-to-oil ratio (cAOR) at the end of the 2 years of combustion is determined and found to be 509 and $533 \mathrm{Sm}^{3}$ air $/ \mathrm{m}^{3}$ oil for reservoir thicknesses of $24 \mathrm{~m}$ and $16 \mathrm{~m}$, respectively. At 417 days, the cAORs are 464,
496, and $514 \mathrm{Sm}^{3}$ air $/ \mathrm{m}^{3}$ oil for $24 \mathrm{~m}, 16 \mathrm{~m}$, and $8 \mathrm{~m}$ reservoir thicknesses, respectively. This shows that the fraction of the heat generated due to the combustion used to heat up the reservoir rock becomes significantly smaller compared to the heat loss with the decrease in reservoir thickness (further explanations are given later). Also, this increasing trend with the decrease in reservoir thickness is the same as that observed experimentally (Xia et al. 2002). However, the values reported here are substantially lower than the nominal value of $1500 \mathrm{Sm}^{3} / \mathrm{m}^{3}$ reported for conventional ISC (Xia et al. 2002). The difference can be explained by the fact that reservoir models with no caprock, no heterogeneity, and no bottom water are used in this study and that the combustion time is only limited 


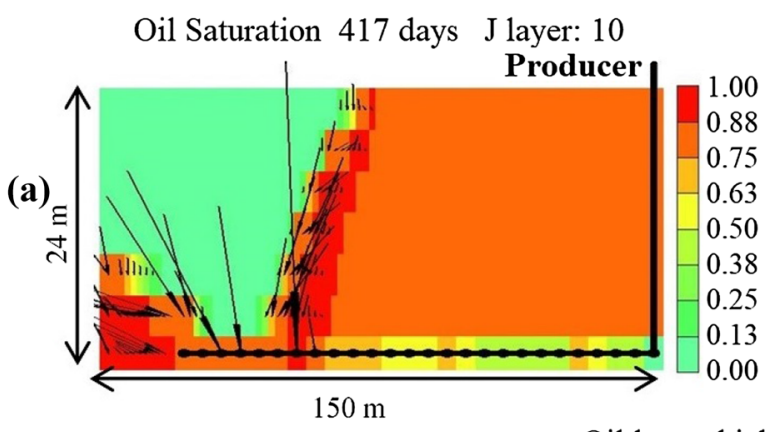

Oil layer thickness: $24 \mathrm{~m}$

Oil Saturation 417 days K layer: 4

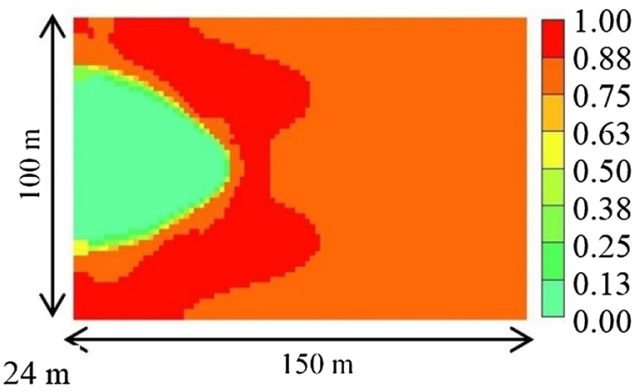

Oil Saturation 417 days K layer: 4

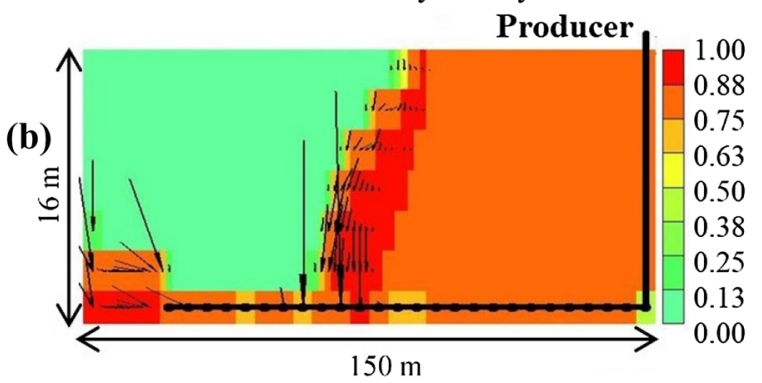

Oil layer thickness: $16 \mathrm{~m}$

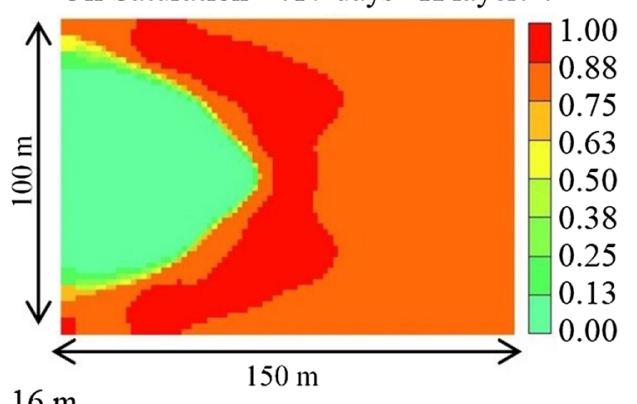

Oil Saturation 417 days J layer: 10

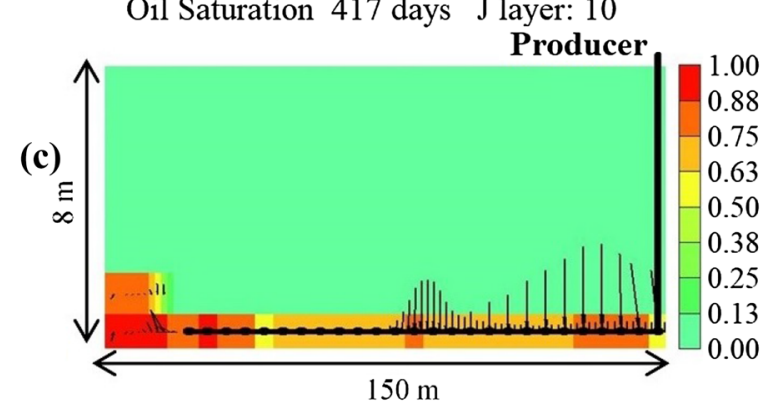

Oil layer thickness: $8 \mathrm{~m}$

Oil Saturation 417 days K layer: 4

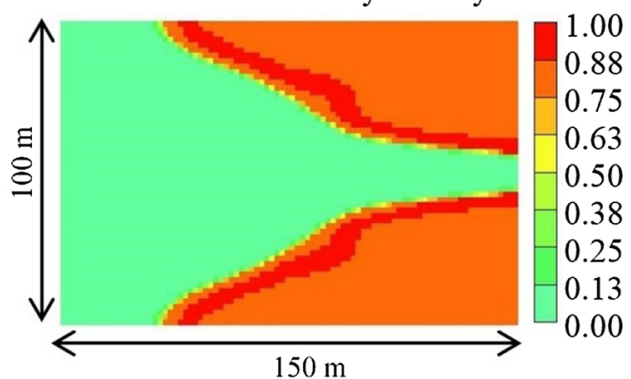

Fig. 5 Oil saturation profiles at 417 days: along the vertical mid-plane (left) and along the horizontal mid-plane (right) at constant air injection rate

to 2 years. Comparing the cAOR for the $24-\mathrm{m}$ reservoir thickness model at different times, it can be seen that the cAOR increases with the combustion time (i.e. $464 \mathrm{Sm}^{3} /$ $\mathrm{m}^{3}$ after 10.5 months of combustion versus $509 \mathrm{Sm}^{3} / \mathrm{m}^{3}$ after 2 years of combustion). The same applies to the model with the reservoir thickness of $16 \mathrm{~m}$ (i.e. $496 \mathrm{Sm}^{3}$ / $\mathrm{m}^{3}$ after 10.5 months of combustion versus $533 \mathrm{Sm}^{3} / \mathrm{m}^{3}$ after 2 years of combustion). As a result, the cAOR is expected to approach the reported value when the process time is increased. Overall, it is concluded that the slight decrease in the cumulative oil production and the increase in cAOR with the decrease in reservoir thickness are due to increased heat loss.

\section{Shape of combustion front}

The smaller the oil layer thickness, the faster the advancement of the combustion front and the larger the fraction of the reservoir swept by the combustion front. This can be observed from Fig. 4, where the comparison is shown. The oxygen concentration profile (Fig. 4a) shows that at 417 days, the combustion front, at the top part of the reservoir, covered one-third of the reservoir length, when the reservoir thickness is $24 \mathrm{~m}$. As the thickness is decreased by $33.3 \%$ to $16 \mathrm{~m}$, the combustion front covered half of the reservoir length at 417 days (Fig. 4b). By further decreasing the oil layer thickness to $8 \mathrm{~m}$, the combustion front covered 
the whole reservoir length at the top of the reservoir as indicated in Fig. 4c. In earlier work, it has been shown from the experimental model that oxygen breakthrough only takes place once the combustion front propagates along the horizontal producer (Rabiu Ado et al. 2017). From the profiles (Fig. 4), it can be observed that as the oil layer thickness decreases, the combustion front advances quickly in all the three directions. This shows that at constant air injection rate, the lower the oil layer thickness, the earlier the oxygen production will take place. It can be observed that at the same air injection rate, the combustion front is much more stable when the oil layer is thickest. This is shown by the 3D shape of the combustion front, in Fig. 4a, left, having the combustion front furthest away from the HP well. The separation between the combustion front and the HP well decreases with the decrease in the reservoir thickness. One way to ensure proper distribution of the combustion front is through scaling of the air injection rate to reflect the decrease in the cross-sectional area of the reservoir. As a result, further study, on an equivalent basis such as the same air flux, or running the process to completion, or both, is needed in order to make comparisons from which decisive conclusion can be drawn.

\section{Oil saturation profiles}

The thinner the oil layer, the larger the fraction of the reservoir oil mobilized and displaced by the heat from the combustion zone (Fig. 5). In accordance with the shape of the combustion front, the thicker the reservoir, the shorter the distance between the inlet zone of the reservoir and the mobile oil zone (MOZ), which is shown by the oil flux vectors superimposed on the 2D profiles. Figure 5a shows that by 417 days, the MOZ is located at about one-third of the reservoir length, while in Fig. 5c which has reservoir thickness of $8 \mathrm{~m}$, all the oil in the vertical mid-plane and above the HP well has been produced. Comparing the vertical (Fig. 5, left) and horizontal profiles (Fig. 5, right), it can be seen that the lower the reservoir thickness, the narrower and longer the swept oil zone. This shows how the stability of the process deteriorates with decrease in reservoir thickness for the same air injection rate. By keeping the producer back pressure to $2800 \mathrm{kPa}$ (406.11 psi), the oil accumulated at the base layer of the reservoir (Fig. 5) and thus essentially prevented oxygen from reaching the horizontal producer while forcing the combustion front to advance faster along the reservoir length (Fig. 4). However, as more air is injected, the combustion front will be forced either to traverse the reservoir or to propagate along the axis of the HP well, hence resulting in oxygen breakthrough. The former scenario takes place at the reservoir thickness of $8 \mathrm{~m}$ (Fig. 5c), which further indicated that the air injection rate must be properly scaled to ensure optimum combustion front propagation.
Furthermore, from the oil saturation plots (Fig. 5) and the oxygen profiles (Fig. 4), it is observed that the mobile oil zone (MOZ) is not far away from the combustion front. Also, the combustion zone temperature was observed to increase with increase in oil layer thickness, which is very similar to the observation made from experiments by Xia et al. (2002).

\section{Constant air injection flux models}

Given the previous findings that the use of constant air injection rate results in oxygen breakthrough occurring sooner in a thin oil layer, because the front velocity is greater, and consequently, there is a greater tonguing effect, it is necessary to investigate how the oil layer thickness affects the performance of the THAI process when constant air flux is used regardless of the reservoir thickness. Therefore, for this second set of the three models (i.e. with the reservoir thicknesses of $24 \mathrm{~m}, 16 \mathrm{~m}$, and $8 \mathrm{~m}$, respectively), at the end of the PHIC, air was injected at the constant flux of $0.347 \mathrm{~m}^{3} / \mathrm{m}^{2} \mathrm{~h}$ regardless of the reservoir thickness. As a result, we refer them as the constant air injection flux models, since by keeping the air injection flux the same in each model, the rate of advancement of the combustion front will be the same, and hence, a comparative study can be made about the extent of oil displacement in the reservoir. The air injection rate, however, is variable. Therefore, the air injection rates are 20,000, 13333.3 , and $6666.7 \mathrm{Sm}^{3} /$ day for the reservoir thicknesses of $24 \mathrm{~m}, 16 \mathrm{~m}$, and $8 \mathrm{~m}$, respectively.

\section{Oil production rate}

At the end of the 104 days of the PIHC, air was injected at the same flux regardless of the reservoir thickness. Unlike when the air injection rate was constant, as can be seen in Fig. 6, the oil production rate curves have essentially the same shape and follow the same trend during most part of the 2 years of combustion. The simulation results show that the lower the reservoir thickness, the lower the oil production rate. This is necessary and as expected, since the air injection rate was decreased with the decrease in the reservoir thickness. Overall, the shapes of the oil production rate curves show that the oil displacement pattern inside the reservoir is quite similar. Note that for the model with the reservoir thickness of $8 \mathrm{~m}$, the combustion was carried out for 632 days compared with the 730 days ( 2 years) in the other models. This was caused by the massive drop in the simulation time step (to less than $10^{-6}$ day) to the extent that it became impractical to let the simulation carry on. It should, however, be noted that this did not in any way affect the accuracy of the simulation results.

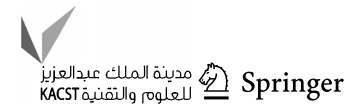


Fig. 6 Oil production rate for the different reservoir thicknesses at constant air injection flux

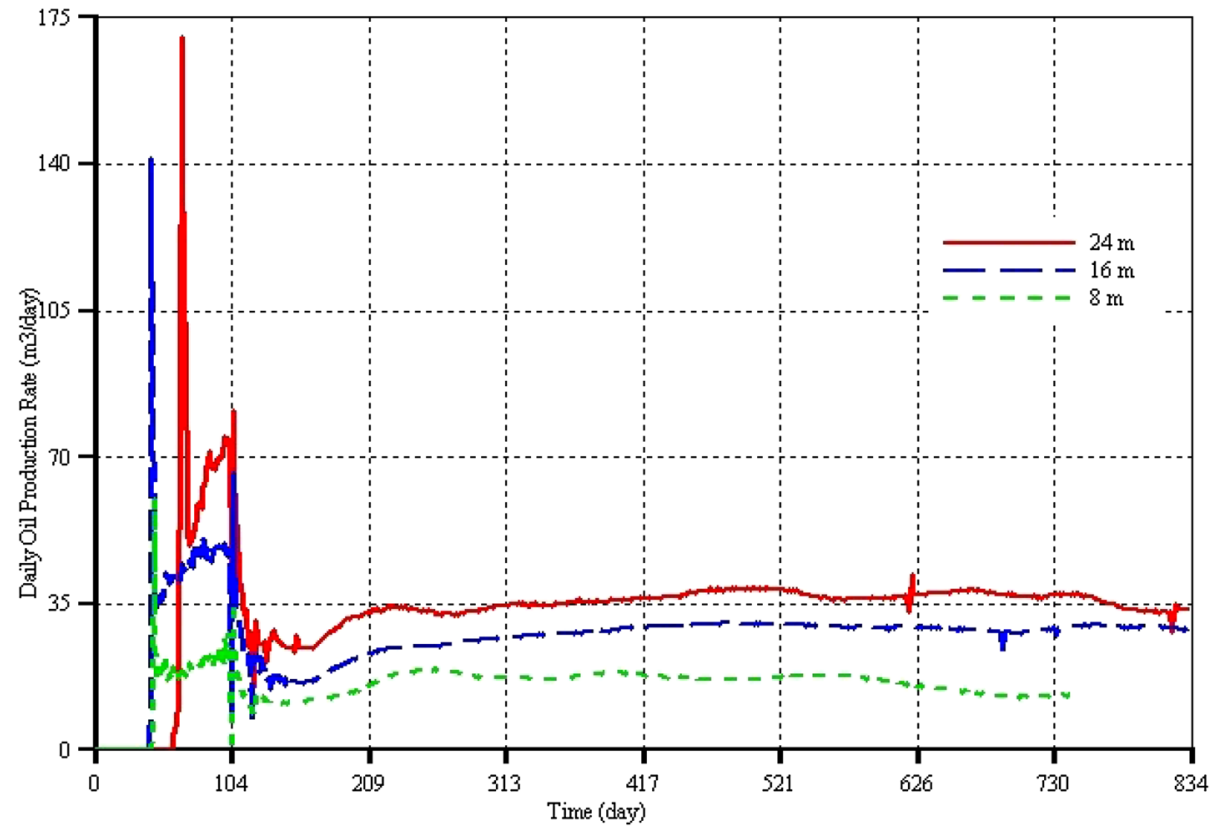

\section{Cumulative oil production}

In sharp contrast to the constant air injection rate models, the cumulative oil production curves for the constant air injection flux models diverge substantially from each other. The divergence increases with the increase in process time and decrease in reservoir thickness. In accordance with the oil production rate curves, the lower the reservoir thickness, and hence the lower the air injection rate, the lower the slope of the cumulative oil production curve (Fig. 7). However, since the air flux is the same, it is expected that the combustion front will sweep the same volume fraction of the reservoir regardless of the reservoir thickness. Consequently, and ideally (i.e. provided there is no heat loss), it follows that the models will have the same cumulative air-to-oil ratio (cAOR). At 730 days (i.e. 626 days after the start of combustion), the cumulative oil produced by the models with the reservoir thicknesses of $24 \mathrm{~m}, 16 \mathrm{~m}$, and $8 \mathrm{~m}$ is 24,800 , 19,800 , and $11,700 \mathrm{~m}^{3}$, respectively. At the same time, the cAOR for models with the reservoir thicknesses of $24 \mathrm{~m}$, $16 \mathrm{~m}$, and $8 \mathrm{~m}$ is, respectively, 505, 422, and $357 \mathrm{Sm}^{3}$ air $/ \mathrm{m}^{3}$ oil. Keeping in mind that these values are significantly lower
Fig. 7 Cumulative oil production for the different reservoir thicknesses at constant air injection flux

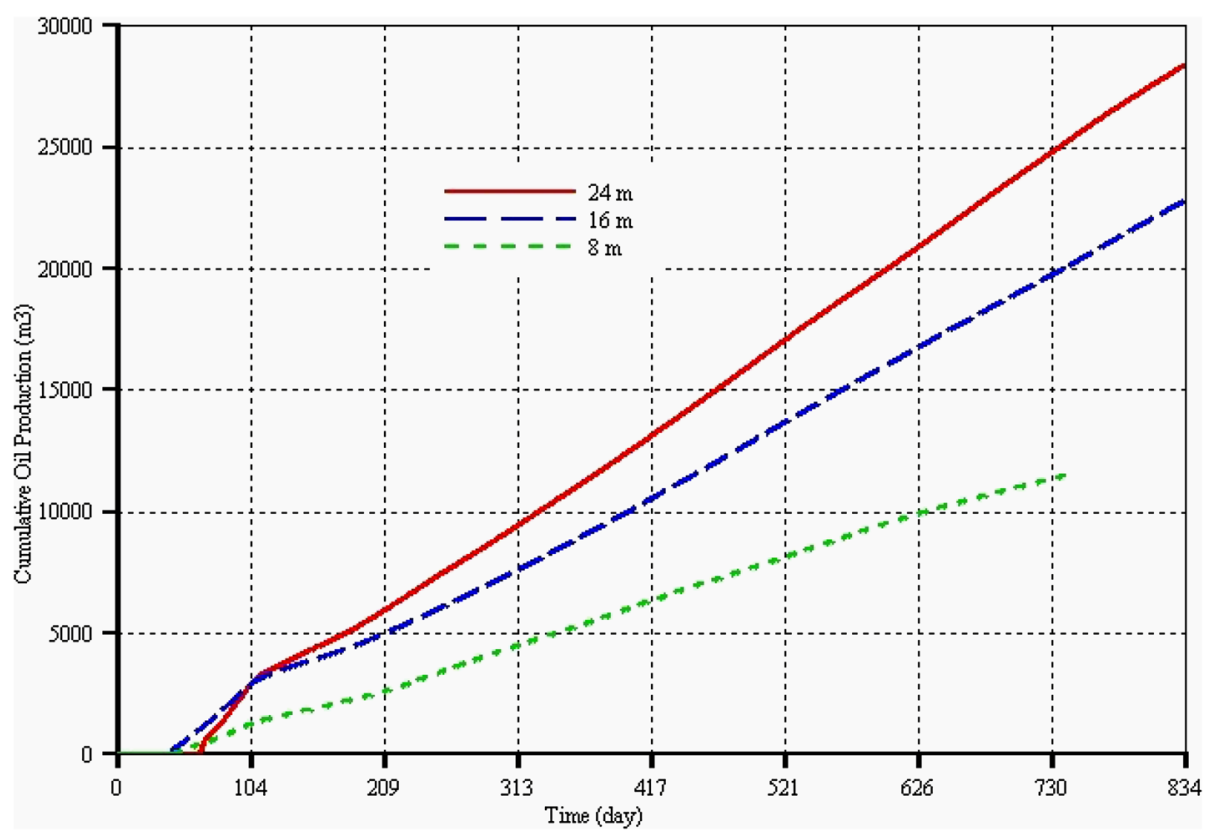


than the nominal value of $1500 \mathrm{Sm}^{3} / \mathrm{m}^{3}$ usually reported for conventional ISC, the trend of decreasing cAOR with the decrease in reservoir thickness for the constant air injection flux models is completely opposite to that for the models with the constant air injection rate. This decrease can be attributed to the decrease in the rate of heat generation in the thinner reservoirs, which in turn results in lower combustion zone temperature and thus a lower temperature gradient between the reservoir and the overburden and the reservoir and the underburden. This shows that the slight negative effect that the reservoir thickness has on the performance of the THAI process at constant air injection rate can turn into positive benefit by keeping the air injection flux constant.

To further buttress the above conclusion, the cumulative oil production and the cAOR of the $24 \mathrm{~m}$ and $16 \mathrm{~m}$ reservoir thicknesses models at the end of the 2 years of combustion are compared. Both the constant air injection rate and constant air injection flux scenario are considered. Table 7 shows that keeping the air injection rate constant (i.e. increasing air injection flux with the decrease in reservoir thickness) resulted in an increase in cAOR with the decrease in reservoir thickness. This can be attributed to the increased heat loss to both overburden and underburden with the decrease in reservoir thickness. It should be noted that the thicker the reservoir, the larger the volume of the reservoir rock available to be heated due to the combustion. However, despite that, the heat loss in the thinner reservoirs, though does not have adverse effect on the performance of the THAI process, is quite considerable to the extent that it is higher than the heat used to heat up the reservoir rock in the thicker reservoirs (Fig. 3). Since the cAOR is an economic indicator of the process, it follows that the THAI process economic return decreases with the decrease in the reservoir thickness at constant air injection rate. On the other side, keeping the air injection flux constant (i.e. decreasing the air injection rate with the decrease in reservoir thickness) resulted in a decrease in cAOR with the decrease in reservoir thickness (Table 7). This shows that the decrease in the air injection rate with the decrease in the reservoir thickness resulted in a decrease in the rate of heat generation which in turn resulted in a decrease in the temperature gradient between the reservoir and both overburden and underburden. Since there is more reservoir rock available to be heated in the thicker reservoir (24 m thickness), a portion of the heat of combustion was used to heat up the reservoir resulting in higher cAOR compared to that of the 16-m-thick reservoir. Heat loss is so small for the 16-m-thick reservoir that it cannot balance the heat used to heat up the reservoir rock in the 24-m-thick reservoir.

A more general conclusion is that decreasing the air injection rate by the same factor the reservoir thickness is decreased (i.e. keeping the air injection flux constant) results in a more economical THAI process operation compared to when the air injection rate is kept constant (i.e. allowing increase in air flux).

\section{Oil saturation profiles and 3D shape of combustion fronts}

The oil saturation profiles and the 3D shape of the combustion front for the two different reservoir thicknesses of $16 \mathrm{~m}$ and $8 \mathrm{~m}$ are shown in Fig. 8. Comparing Fig. $8 \mathrm{a}$ and Fig. 5b (left), the shape of the oil saturation profiles is quite identical regardless of whether the air injection rate was kept constant or was varied. This is despite the fact that the former was at 417 days (i.e. 313 days after the start of air injection), while the latter was at 834 days (i.e. 730 days after the start of air injection). However, the location of the MOZ is longer in the latter case, especially considering the fact that the cumulative air injected in the latter case is $55.5 \%$ higher than in the former. Comparing Fig. 8a and c, it can be seen that in the latter, the MOZ is located at longer distance away from the toe of the HP well. This implies that larger fraction of the reservoir volume is swept when the reservoir thickness was decreased by $50 \%$ (i.e. from 16 to $8 \mathrm{~m}$ ). Also, all the two figures show that each of the process is very stable as the shape of the MOZ is forward leaning. The shape of the combustion fronts (Fig. 8b, d) is very well structured and forwarding leaning, which in all the two cases indicate a sign of stability. Just like in the constant air injection rate models, the use of $2800 \mathrm{kPa}(406.11 \mathrm{psi})$ as the producer back pressure resulted in the combustion front not coming into direct contact with the HP well. This is because of the presence of the bottom oil layer which also prevents oxygen from getting into the HP well and be produced. At the reservoir thickness of $8 \mathrm{~m}$, a clear difference can be seen when Fig. 8c is compared to
Table 7 Results comparison for the constant air injection rate versus constant air injection flux after 2 years of combustion

\begin{tabular}{|c|c|c|c|c|c|c|}
\hline \multirow[t]{2}{*}{$\begin{array}{l}\text { Reservoir } \\
\text { thickness (m) }\end{array}$} & \multicolumn{3}{|c|}{$\begin{array}{l}\text { Constant air injection rate }\left(20,000 \mathrm{Sm}^{3} /\right. \\
\text { day) }\end{array}$} & \multicolumn{3}{|c|}{ Constant air injection flux $\left(0.347 \mathrm{~m}^{3} / \mathrm{m}^{2} \mathrm{~h}\right)$} \\
\hline & $\begin{array}{l}\text { Air flux } \\
\left(\mathrm{m}^{3} / \mathrm{m}^{2} \mathrm{~h}\right)\end{array}$ & $\begin{array}{l}\text { Cumulative oil } \\
\text { production }\left(\mathrm{m}^{3}\right)\end{array}$ & $\begin{array}{l}\mathrm{cAOR} \\
\left(\mathrm{Sm}^{3} /\right. \\
\left.\mathrm{m}^{3}\right)\end{array}$ & Air rate $\left(\mathrm{Sm}^{3} /\right.$ day $)$ & $\begin{array}{l}\text { Cumulative oil } \\
\text { production }\left(\mathrm{m}^{3}\right)\end{array}$ & $\begin{array}{l}\mathrm{cAOR} \\
\left(\mathrm{Sm}^{3} /\right. \\
\left.\mathrm{m}^{3}\right)\end{array}$ \\
\hline 24 & 0.347 & 28,700 & 509 & 20,000 & 28,700 & 509 \\
\hline 16 & 0.521 & 27,380 & 533 & 13333.3 & 22,917 & 425 \\
\hline
\end{tabular}



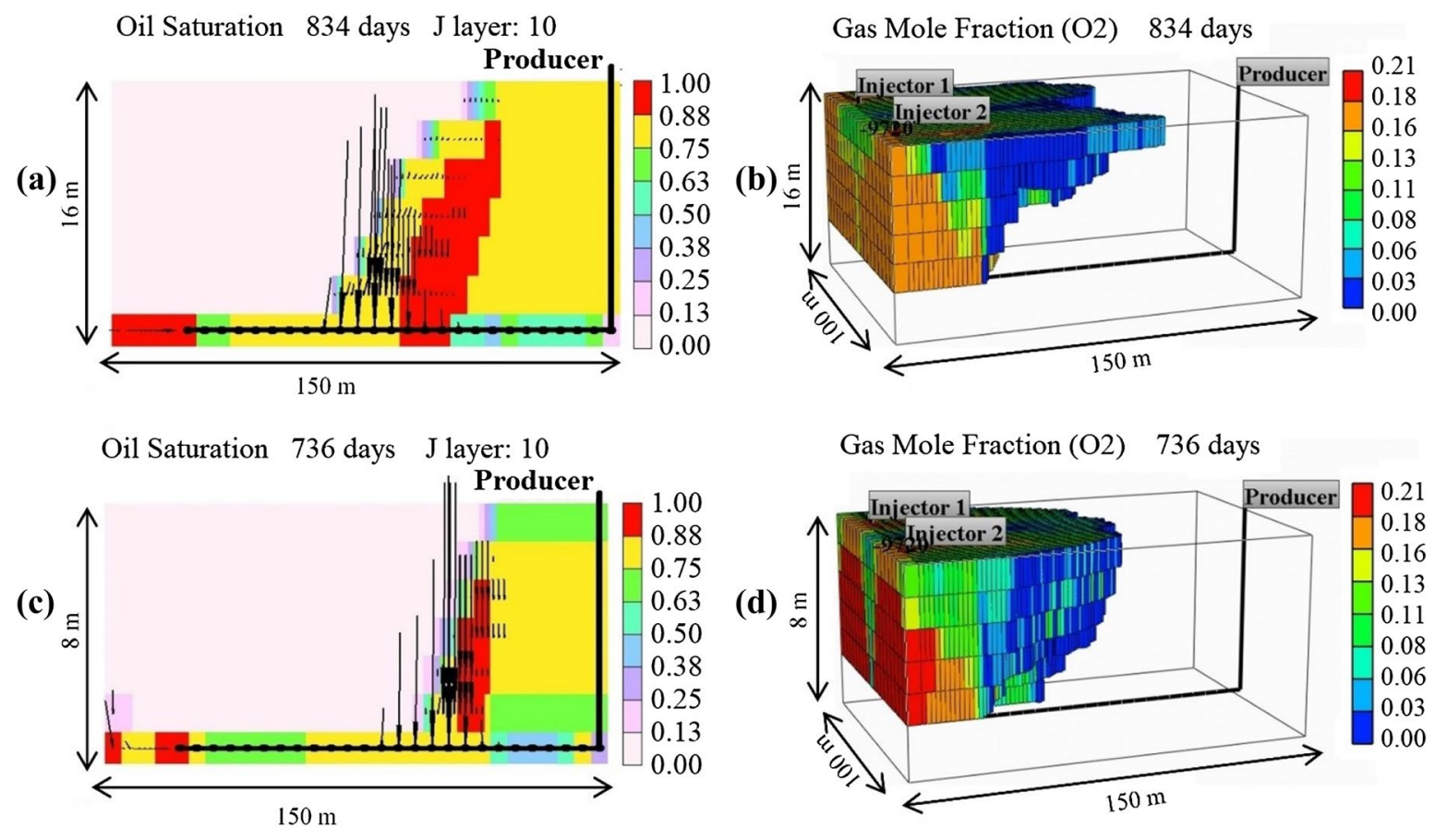

Fig. 8 Oil saturation profiles along vertical mid-plane (left) and 3D shape of combustion front (right) for the constant air injection flux models

Fig. 5c (left). In the former, there is still a cold oil zone, which increases stability, ahead of the MOZ.

\section{Summary and conclusion}

In this work, field-scale kinetics scheme and its parameters are used to study the effect of reservoir pay thickness on the performance of the THAI process. It has been shown that the use of steam for the pre-ignition heating cycle (PIHC) allowed fluid communication to be established between the vertical injectors and the horizontal producer in each model. It is shown that by the end of the PIHC period (i.e. 104 days), the cumulative oil recovered increased with the increase in reservoir thickness. This is despite the higher steam injection flux at lower reservoir thickness. It is concluded that just like in the case of the steam-based recovery processes, the slight decrease in cumulative oil recovery with the decrease in reservoir thickness is due to the increased heat loss to both overburden and underburden.

After the PIHC, air was injected at constant rate into three different models with the reservoir thicknesses of $24 \mathrm{~m}$, $16 \mathrm{~m}$, and $8 \mathrm{~m}$. It was found that no oxygen production took place in any of the models. Since the rate of heat generation was the same, the cumulative oil production curves are found to be very close to each other, indicating that the cumulative oil produced is not very sensitive to the reservoir thickness. It is also found that the lower the reservoir thickness, the larger the cAOR, showing that heat loss increases with the decrease in the reservoir thickness. This is a similar trend to steam-based process. Overall, even though the economic return of the THAI process slightly decreases with the decrease in reservoir thickness, it is concluded that the THAI process is not adversely affected by the reservoir pay thickness for the same air injection rate.

To further support the above conclusion, the three models were run with the same air injection flux so that the fraction of the reservoir to be swept by the combustion front will be the same regardless of the reservoir thickness and so that comparison can be drawn. It was found that the cumulative oil produced increases with the increase in the reservoir thicknesses, which is as expected since the air injection rate also increases with the increase in reservoir thickness. However, what is remarkable is that at any given time, the cAOR for models with the reservoir thicknesses of $24 \mathrm{~m}, 16 \mathrm{~m}$, and $8 \mathrm{~m}$ is, respectively, 505, 422, and $357 \mathrm{Sm}^{3}$ air $/ \mathrm{m}^{3}$ oil. Keeping in mind that these values are significantly lower than the nominal value of $1500 \mathrm{Sm}^{3} / \mathrm{m}^{3}$ usually reported for conventional ISC, the trend of decreasing cAOR with the decrease in reservoir thickness for the constant air injection flux models is completely opposite to that for the models with the constant air injection rate. This decrease is attributed to the decrease in the rate of heat generation in the thinner reservoirs, which in turn results in lower combustion zone temperature and thus a lower temperature gradient between the reservoir and the overburden and the reservoir and the underburden. This shows that the slight negative effect that the reservoir thickness has on the performance of 
the THAI process at constant air injection rate can turn into positive benefit by keeping the air injection flux constant.

In general, it is therefore concluded that for the same air injection rate, at a reservoir thickness of $24 \mathrm{~m}$, the heat needed to heat up the extra volume of reservoir rock $(33.3 \%$ extra compared to when the reservoir thickness is $16 \mathrm{~m}$ ) is smaller than the heat loss from the reservoir when the thickness is reduced by $33.3 \%$. As a result, the cAOR is larger when the reservoir thickness (and thus volume) was decreased by $33.3 \%$. For the same air injection flux, at a reservoir thickness of $24 \mathrm{~m}$, the heat needed to heat up the extra volume of the reservoir rock is much more than the heat loss from the reservoir when the reservoir thickness (and thus volume) was reduced by $33.3 \%$. A more general conclusion is that decreasing the air injection rate by the same factor the reservoir thickness is decreased (i.e. keeping the air injection flux constant) results in a more economical THAI process operation compared to when the air injection rate is kept constant (i.e. allowing increase in air flux).

Funding The author is gratefully acknowledging the Deanship of Scientific Research at King Faisal University, Saudi Arabia, for the financial support under Nasher Track (Grant No. 186272). Also, as part of this work was carried out whilst the author was a PhD student at the University of Nottingham, the author is grateful to the Deans of Engineering for the Deans of Engineering Research Scholarship for International Excellence.

Open Access This article is licensed under a Creative Commons Attribution 4.0 International License, which permits use, sharing, adaptation, distribution and reproduction in any medium or format, as long as you give appropriate credit to the original author(s) and the source, provide a link to the Creative Commons licence, and indicate if changes were made. The images or other third party material in this article are included in the article's Creative Commons licence, unless indicated otherwise in a credit line to the material. If material is not included in the article's Creative Commons licence and your intended use is not permitted by statutory regulation or exceeds the permitted use, you will need to obtain permission directly from the copyright holder. To view a copy of this licence, visit http://creativecommons.org/licenses/by/4.0/.

\section{References}

Ado MR (2019) A detailed approach to up-scaling of the Toe-to-Heel Air Injection (THAI) In-Situ Combustion enhanced heavy oil recovery process. J Pet Sci Eng 173:106740

Ado MR (2020a) Predictive capability of field scale kinetics for simulating toe-to-heel air injection heavy oil and bitumen upgrading and production technology. J Pet Sci Eng 187:106843

Ado MR (2020b) Simulation study on the effect of reservoir bottom water on the performance of the THAI in situ combustion technology for heavy oil/tar sand upgrading and recovery. SN Appl Sci 2:29

Ado MR, Greaves M, Rigby SP (2019) Numerical simulation of the impact of geological heterogeneity on performance and safety of THAI heavy oil production process. J Pet Sci Eng 173:1130-1148
Alamatsaz A, Moore GR, Mehta SA, Ursenbach MG (2019) Visualization of fire flood behavior under declining air flux. Fuel 237:720-734

Al-Bahlani A-M, Babadagli T (2009) SAGD laboratory experimental and numerical simulation studies: a review of current status and future issues. J Pet Sci Eng 68:135-150

Amirian E, Dejam M, Chen Z (2018) Performance forecasting for polymer flooding in heavy oil reservoirs. Fuel 216:83-100

Chen Y-F, Pu W-F, Liu X-L, Li Y-B, Varfolomeev MA, Hui J (2019) A preliminary feasibility analysis of in situ combustion in a deep fractured-cave carbonate heavy oil reservoir. J Pet Sci Eng 174:446-455

Coats K (1983) Some observations on field-scale simulation of the in situ combustion process. In: SPE reservoir simulation symposium, Society of Petroleum Engineers

Dejam M (2018) Dispersion in non-Newtonian fluid flows in a conduit with porous walls. Chem Eng Sci 189:296-310

Dejam M, Ghazanfari MH, Mashayekhizadeh V, Kamyab M (2011) Factors affecting the gravity drainage mechanism from a single matrix block in naturally fractured reservoirs. Spec Top Rev Porous Media Int J 2:115-124

Dejam M, Hassanzadeh H, Chen Z (2013) Semi-analytical solutions for a partially penetrated well with wellbore storage and skin effects in a double-porosity system with a gas cap. Transp Porous Media 100:159-192

Dejam M, Hassanzadeh H, Chen Z (2018) Shear dispersion in a roughwalled fracture. SPE J 23:1669-1688

Fatemi SM (2012) The effect of geometrical properties of reservoir shale barriers on the performance of steam-assisted gravity drainage (SAGD). Energy Sources Part A Recovery Util Environ Eff 34:2178-2191

Gates ID (2010) Solvent-aided Steam-Assisted Gravity Drainage in thin oil sand reservoirs. J Pet Sci Eng 74:138-146

Gates ID, Larter SR (2014) Energy efficiency and emissions intensity of SAGD. Fuel 115:706-713

Greaves M, Xia TX, Turta AT (2008) Stability of THAI (TM) process-theoretical and experimental observations. J Can Pet Technol 47:65-73

Gutierrez D, Skoreyko F, Moore R, Mehta S, Ursenbach M (2009) The challenge of predicting field performance of air injection projects based on laboratory and numerical modelling. J Can Pet Technol 48:23-33

Huang S, Chen X, Liu H, Xia Y, Jiang J, Cao M, Li A, Yang M (2019) Experimental and numerical study of steam-chamber evolution during solvent-enhanced steam flooding in thin heavy-oil reservoirs. J Pet Sci Eng 172:776-786

Hwang M, Jines W, Odeh A (1982) An In-Situ combustion process simulator with a moving-front representation. Soc Pet Eng J 22:271-279

Ito Y, Chow AK-Y (1988) A field scale in situ combustion simulator with channeling considerations. SPE Reserv Eng 3:419-430

Kovscek A, Castanier L, Gerritsen M (2013) Improved predictability of In-Situ-combustion enhanced oil recovery. SPE Reserv Eval Eng 16:172-182

le Ravalec M, Morlot C, Marmier R, Foulon D (2009) Heterogeneity impact on SAGD process performance in mobile heavy oil reservoirs. Oil Gas Sci Technol Revue de l'IFP 64:469-476

Liang J, Guan W, Jiang Y, Xi C, Wang B, Li X (2012) Propagation and control of fire front in the combustion assisted gravity drainage using horizontal wells. Pet Explor Dev 39:764-772

Marjerrison D, Fassihi MA (1992) Procedure for scaling heavy-oil combustion tube results to a field model. In: SPE/DOE enhanced oil recovery symposium, Society of Petroleum Engineers

Mashayekhizadeh V, Dejam M, Ghazanfari MH (2011a) The application of numerical laplace inversion methods for type curve

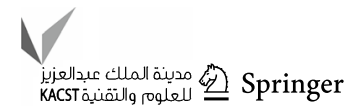


development in well testing: a comparative study. Pet Sci Technol 29:695-707

Mashayekhizadeh V, Ghazanfari MH, Kharrat R, Dejam M (2011b) Pore-level observation of free gravity drainage of oil in fractured porous media. Transp Porous Media 87:561-584

Meyer RF, Attanasi ED, Freeman PA (2007) Heavy oil and natural bitumen resources in geological basins of the world. U.S. Geological Survey Open-File Report 2007-1084

Nissen A, Zhu Z, Kovscek A, Castanier L, Gerritsen M (2015) Upscaling kinetics for field-scale In-Situ-combustion simulation. SPE Reserv Eval Eng 18:158-170

PETROBANK 2010 (2008) Annual Progress Report for White Sands Experimental Project

Rabiu Ado M (2017) Numerical simulation of heavy oil and bitumen recovery and upgrading techniques. Ph.D. thesis, University of Nottingham

Rabiu Ado M, Greaves M, Rigby SP (2017) Dynamic simulation of the toe-to-heel air injection heavy oil recovery process. Energy Fuels 31:1276-1284

Rabiu Ado M, Greaves M, Rigby SP (2018) Effect of pre-ignition heating cycle method, air injection flux, and reservoir viscosity on the THAI heavy oil recovery process. J Pet Sci Eng 166:94-103

Rahnema H, Barrufet M, Mamora DD (2017) Combustion assisted gravity drainage-Experimental and simulation results of a promising in situ combustion technology to recover extra-heavy oil. J Pet Sci Eng 154:513-520

Saboorian-Jooybari H, Dejam M, Chen Z (2015) Half-century of heavy oil polymer flooding from laboratory core floods to pilot tests and field applications. In: SPE Canada heavy oil technical conference, Society of Petroleum Engineers, Calgary

Saboorian-Jooybari H, Dejam M, Chen Z (2016) Heavy oil polymer flooding from laboratory core floods to pilot tests and field applications: half-century studies. J Pet Sci Eng 142:85-100

Shi L, Xi C, Liu P, Li X, Yuan Z (2017) Infill wells assisted in situ combustion following SAGD process in extra-heavy oil reservoirs. J Pet Sci Eng 157:958-970

Su Y, Wang JY, Gates ID (2013) SAGD well orientation in point bar oil sand deposit affects performance. Eng Geol 157:79-92

Su Y, Wang J, Gates ID (2014) Orientation of a pad of SAGD well pairs in an Athabasca point bar deposit affects performance. Mar Pet Geol 54:37-46

Sun F, Li C, Cheng L, Huang S, Zou M, Sun Q, Wu X (2017a) Production performance analysis of heavy oil recovery by cyclic superheated steam stimulation. Energy 121:356-371
Sun F, Yao Y, Chen M, Li X, Zhao L, Meng Y, Sun Z, Zhang T, Feng D (2017b) Performance analysis of superheated steam injection for heavy oil recovery and modeling of wellbore heat efficiency. Energy 125:795-804

Sun F, Yao Y, Li G, Li X, Li Q, Yang J, Wu J (2018) A coupled model for $\mathrm{CO}_{2}$ and superheated steam flow in full-length concentric dualtube horizontal wells to predict the thermophysical properties of $\mathrm{CO}_{2}$ and superheated steam mixture considering condensation. $\mathbf{J}$ Pet Sci Eng 170:151-165

Turta A, Singhal A (2004) Overview of short-distance oil displacement processes. J Can Pet Technol 43:20

Wang Y, Ren S, Zhang L (2019) Mechanistic simulation study of air injection assisted cyclic steam stimulation through horizontal wells for ultra heavy oil reservoirs. J Pet Sci Eng 172:209-216

Xia T, Greaves M (2002) Upgrading Athabasca tar sand using toe-toheel air injection. J Can Pet Technol 41:35

Xia T, Greaves B, Werfilli M, Rathbone R (2002) THAI process-effect of oil layer thickness on heavy oil recovery. In: Canadian international petroleum conference

Xia T, Greaves M, Turta A (2005) Main mechanism for stability of THAI-Toe-to-Heel Air Injection. J Can Pet Technol 44:23

You N, Yoon S, Lee CW (2012) Steam chamber evolution during SAGD and ES-SAGD in thin layer oil sand reservoirs using a 2-D scaled model. J Ind Eng Chem 18:2051-2058

Zhao DW, Wang J, Gates ID (2013) Optimized solvent-aided steamflooding strategy for recovery of thin heavy oil reservoirs. Fuel 112:50-59

Zhao DW, Wang J, Gates ID (2014) Thermal recovery strategies for thin heavy oil reservoirs. Fuel 117:431-441

Zhao R, Yu S, Yang J, Heng M, Zhang C, Wu Y, Zhang J, Yue X-A (2018) Optimization of well spacing to achieve a stable combustion during the THAI process. Energy 151:467-477

Zhao S, Pu W, Sun B, Gu F, Wang L (2019) Comparative evaluation on the thermal behaviors and kinetics of combustion of heavy crude oil and its SARA fractions. Fuel 239:117-125

Publisher's Note Springer Nature remains neutral with regard to jurisdictional claims in published maps and institutional affiliations. 